\title{
Risk assessment in the field of museum resource management: Objects preventive conservation approach
}

\author{
S. Sharif ${ }^{\mathrm{a}}$, A. Zamani Fard ${ }^{\mathrm{a}^{*}}$ and V. Esmaeili ${ }^{\mathrm{b}}$
}

${ }^{a}$ Faculty of Applied Arts, University of Art, Tehran, Iran ${ }^{b}$ School of Industrial Engineering, Iran University of Science and Technology, Tehran, Iran

\section{H R O N I C L E}

Article history:

Received June 10, 2013

Received in revised format

25 August 2013

Accepted September 262013

Available online

September 292013

Keywords:

Risk

Risk Assessment

Museum

Preventive Conservation

Museum Resource Management

Objects service life

\begin{abstract}
A B S T R A C T
Cultural heritage and properties in collections are the most important organizational resources of museums, which can be deteriorated under improper environmental conditions. Identifying the climate deteriorating agents, and assessing and prioritizing their risk levels are among the most recent issues studied by museum conservators and researchers. Creating risk management programs leads to enhancing service life of cultural properties. Temperature and relative humidity are two important factors related directly to objects permanence; Thus, using methods which combine and quantify the conservation effects of temperature and relative humidity, could yield to useful and reliable insights for proposition of effective preventive conservation solutions. This research tries to explain the role and importance of risk management programs in the museums -as one of the main pillars of the country's cultural heritage; therefore, by using a multidisciplinary approach and existing experiments, proposes a method to examine and assess risks of temperature and relative humidity on museum objects. Such quantitative analysis could help estimate objects' service life and provide solutions in order to enhance it. In order to examine the proposed research method, temperature and relative humidity data were gathered from textile storage room of the Cultural Institute of Bonyad Museums in a period of 18 months.
\end{abstract}

(C) 2013 Growing Science Ltd. All rights reserved.

\section{Introduction}

Conservation consists of every effort to keep cultural properties for future generation and its objective, is to study, record, maintain, and restore a valuable cultural object with minimum intervention (CCI, 1985). Preventive conservation is determined as indirect actions to reduce objects deterioration and prevention of possible damages, which can be obtained by providing optimum conditions for cultural heritage and considering consistency of its social function (ECCO, 2013). The primary objective of preventive conservation is to enhance museum objects' service life and to reduce deterioration and damages to historical objects in order to decrease, postpone, or wipe out restoration activities (AIC, 2003). Assessment of environmental conditions on deterioration of museum objects is, without doubt, one of the most significant issues in preventive conservation goals. Estimation of objects service life makes prediction of conservational activities possible, in order to reduce

* Corresponding author. Tel.: +98 91 9828-7485

E-mail addresses: zamanifard@art.ac.ir (A. Zamani Fard)

(C) 2013 Growing Science Ltd. All rights reserved. doi: $10.5267 /$ j.uscm.2013.09.005 
environmental risks. This, in turn, will lead to conjugate programs and increase in personnel cooperation and participation in conservation of cultural heritage.

Risk management, which has been introduced and implemented to conservation area, is one of the most proper methods to create integrity in the Knowledge of museum staffs to provide strategies that are more efficient and determine priorities for museum resource management. It can be perceived that using risk management principles in conservation of historical and cultural objects could be yield through these steps:

1- Identifying hazards and risks associated with the objects

2- Prioritizing risks based on the magnitude (intensity) and value of cultural property, which is endangered.

Different techniques could be used to describe and to evaluate intensity and probability for risks. Based on the quantitative or qualitative method, various indexes could be implemented. Hazard classification is different based on intensity, frequency, and number of occurrence. Meanwhile, temperature and relative humidity are among gradual and constant risks, which can be evaluated through accurate and continuing monitoring system. Changes in temperature and relative humidity are two most significant factors that have direct relationship with vulnerability of objects. By considering effects of temperature and relative humidity on chemical deterioration rate in museum collections, it is possible to calculate service life of organic objects. Consequently, quality of environmental conditions of present and future will be quantified in associate with collection damages (Reilly et al., 1995). Since temperature and relative humidity are quantitative parameters, it is possible to use quantitative methods to assess risks, associated to improper storage conditions of galleries and storage rooms in museums. After identifying threats and hazards and assessing magnitude and intensity of risks, feasible solutions for damage control can be provided.

Risk assessment, as the core of risk management process, can provide correct prioritization of conservation activities. Using quantitative approaches can help develop methods for curators and staffs to have the ability to make long-term assessments of climate effects on museum objects and collections in the storage rooms, without specialized knowledge on engineering and other fields of science. The ability to quantify the intensity of climate conditions of storage rooms on collections service life is predecessor for changes and innovations in physical and storage conditions of buildings like installing air conditioning systems or improving its functions (Sebera, 1994).

Early studies of risk management in the field of museum resource management and conservation were assigned for introduction of concept, techniques, and quantitative tools that could be used by conservators and curators. Waller (1994), in his studies tried to identify, classify, and prioritize intensity and frequency of all risks that could be associated with museum objects; He considered risk assessment as preventive conservation strategy for resource management and proposed risk management as a decision-making approach for preventive conservation of a collection or a group of museum collections. Michalski (1994, 2004) emphasized on building a new perspective in collection conservation as a part of an overall system - instead of focusing on small details- and tried to replace scattered actions with a systematic and holistic approach in museum.

Keene (1996) extended the use of quantitative techniques and statistical methods in risk management and discussed their value for conservators and other museum specialists. Ashley-Smith (1999) explained the mechanisms of declining museum objects, as well as quantification of damages and estimation of rate of deteriorations. Waller (1999) classified risks based on probability of occurrence and intensity into three categories: 1) rare and catastrophic, 2) sporadic and severe, and 3) gradual and constant. Bacci et al. (2000) emphasized on the importance of monitoring and control on climate parameters in order to apply it in quantitative methods implemented to reduce objects deteriorations. 
Analyzing cultural properties and heritage, Waller (2003) introduced CPRAM ${ }^{1}$ model to determine priorities for resource allocation to preventive conservation. Waller and Michalski (2005) discussed Paradigm Shift in preventive conservation and replacing traditional methods with risk management tools and highlighted the importance of changing perspectives in conservators and curators as well as museum managers.

There have been many researches about the role of conservation and preventive conservation for historical climates. Their focus is mostly on decrease in variations of temperature and relative humidity due to different museum standards about objects conservation. Some of these researchers investigated techniques of measuring environmental qualities in microclimates (Schieweck et al., 2007) while, others like Reilly et al. (2007), Pinheiro \& Macedo (2009), Schijndel et al., (2011) and Huijbregts et al., (2012) criticized the application of these measurements in order to determine climate deteriorating potency on objects in different ways. Finally, Martens (2012) focused on climate risk assessment in museums considering temperature and relative humidity as most important factors. Simulating different museum environments in his study, helped investigate effects of climate change on objects deterioration.

Recent studies in the field of conservation show that different quantitative methods have helped researchers prioritize risks of museum collections and develop preventive procedures to reduce hazards. Trends in new studies also indicate that collection management and conservation are now prepared to use new methods and ideas that give more priority to quantitative analysis and provide quantifiable conservational procedures with measurable indexes; as it can be perceived from published papers and researches like Waller (1994 \& 1995), Waller and Shelton (1989), and Baer (1991). Moreover, despite the aid of modern technologies used to gauge and to monitor temperature and relative humidity, conservation field still does not have necessary methods and tools to quantify and to assess the interaction between these two parameters and its effect on deterioration of different materials; due to complexity of computation methods, curators and conservators usually don't have sufficient skills to interpret long-term effects of environmental data that has been gathered. Therefore, it seems developing methods that can be used to assess risks associated with temperature and relative humidity and their interaction on museum collections, is one of the main goals of preventive conservation, which can affect decision-making process of managers.

\section{Risk management process for museum cultural objects}

Preventive conservation attempts to inform managers about existing tools and methods that can help dealing with the complex system of cultural property management. While using systematic or heuristic approaches, three primary assumptions should be considered that have direct influence on conservators work: 1) Self-sufficiency- a feeling that leads to decision-making of an individual, 2) incentive -to make a right decision, and 3) adequacy of information- availability of enough information to make a decision, (Waller, 2003, p.15). Risk analysis can be applied to make consistent decisions in uncertain conditions of complex systems, so its advantages have been recognized by collection management field. Although, due to lack of one the three above assumptions, there has been significant gaps between researches and their implementation in conserving cultural properties and works of art.

\subsection{Cultural collections management system}

Institutes like museums and other similar associations, work together under a superior system as cultural heritage organizations. Each museum, preserve some collections of objects and has a function named "collection management". This function has three sub-systems that are use, development, and

\footnotetext{
${ }^{1}$ Cultural Property Risk Analysis Model
} 
conservation. Fig. 1 displays relationships and effects among these three sub-systems and their affiliation with collection management function.

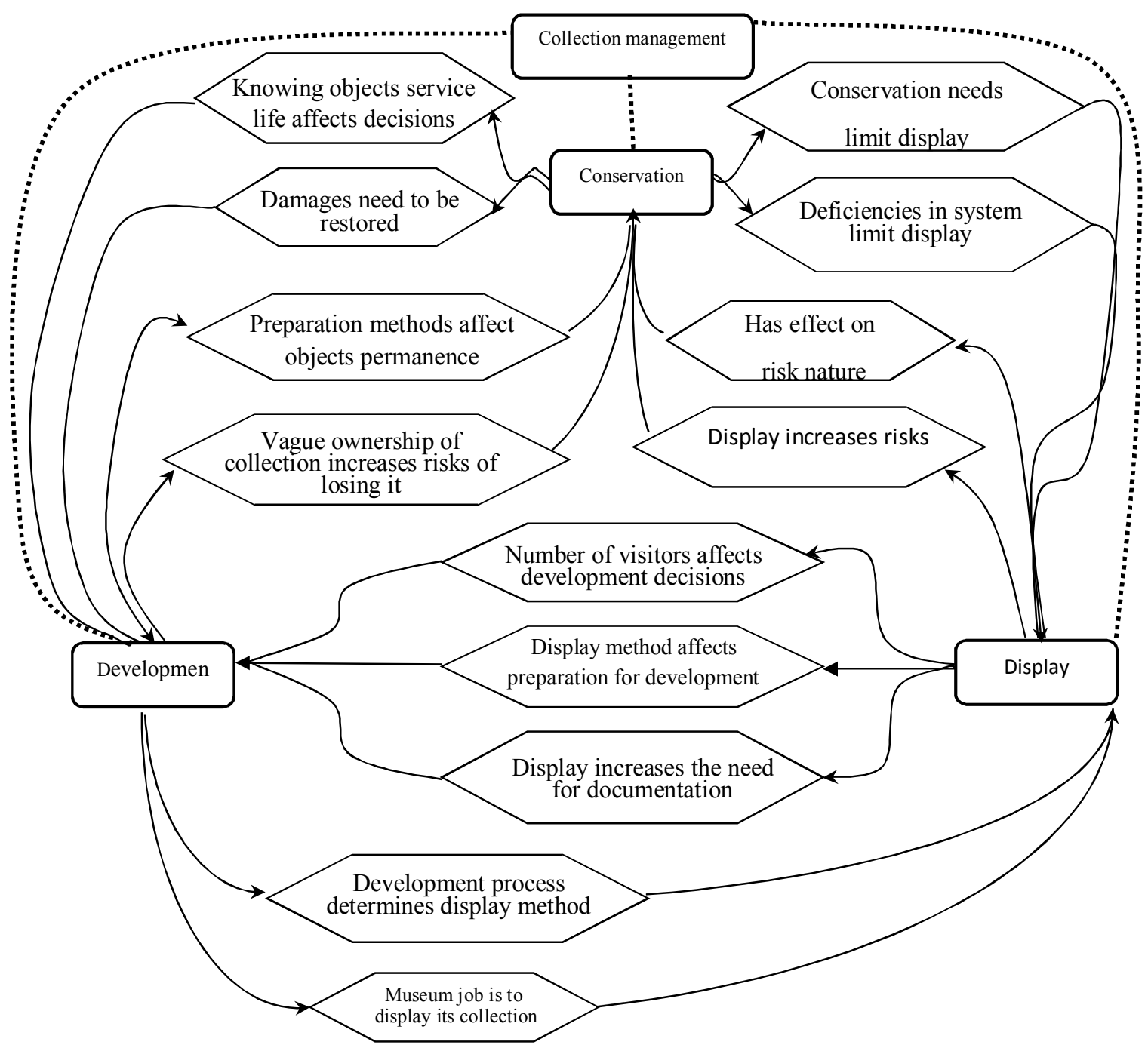

Fig. 1. Relationships and effects of sub-systems in museum collection management (Waller, 2003)

Arrows show direction of influences, and often, a reverse flow displays feedback on the data. Dashed curves show connection of sub-systems with collection management function. The above diagram emphasizes that collection management has to create a balance between conservational and financial goals of a museum; with this balance, it is possible to create proper conservational conditions, as well as collection development.

\subsection{Cultural heritage risk management framework}

Developing risk management programs for cultural heritages has several advantages and taking advantage of risk management is a noteworthy matter for conservators, which enhances their abilities to care for cultural heritage resources. Using risk management programs in conservations has two major advantages: first, increasing service life of cultural objects and works of art that can be obtained through hazard identification and management. Second, applying cultural heritage risk management framework that changed the focus of conservators, from restoration to preventive programs, and from shot-term outlook to long-term visions, which leads to efficiency and effectiveness of their organizational resources (Stovel, 1998, p.16) 
Risk management is the process of comparing risk analysis results with risk criterions in order to determine acceptance, allowable or reject levels (ISO 31000). As it is displayed in Fig. (2), risk management includes risk assessment and control. Risk assessment consists of risk analysis and evaluation.

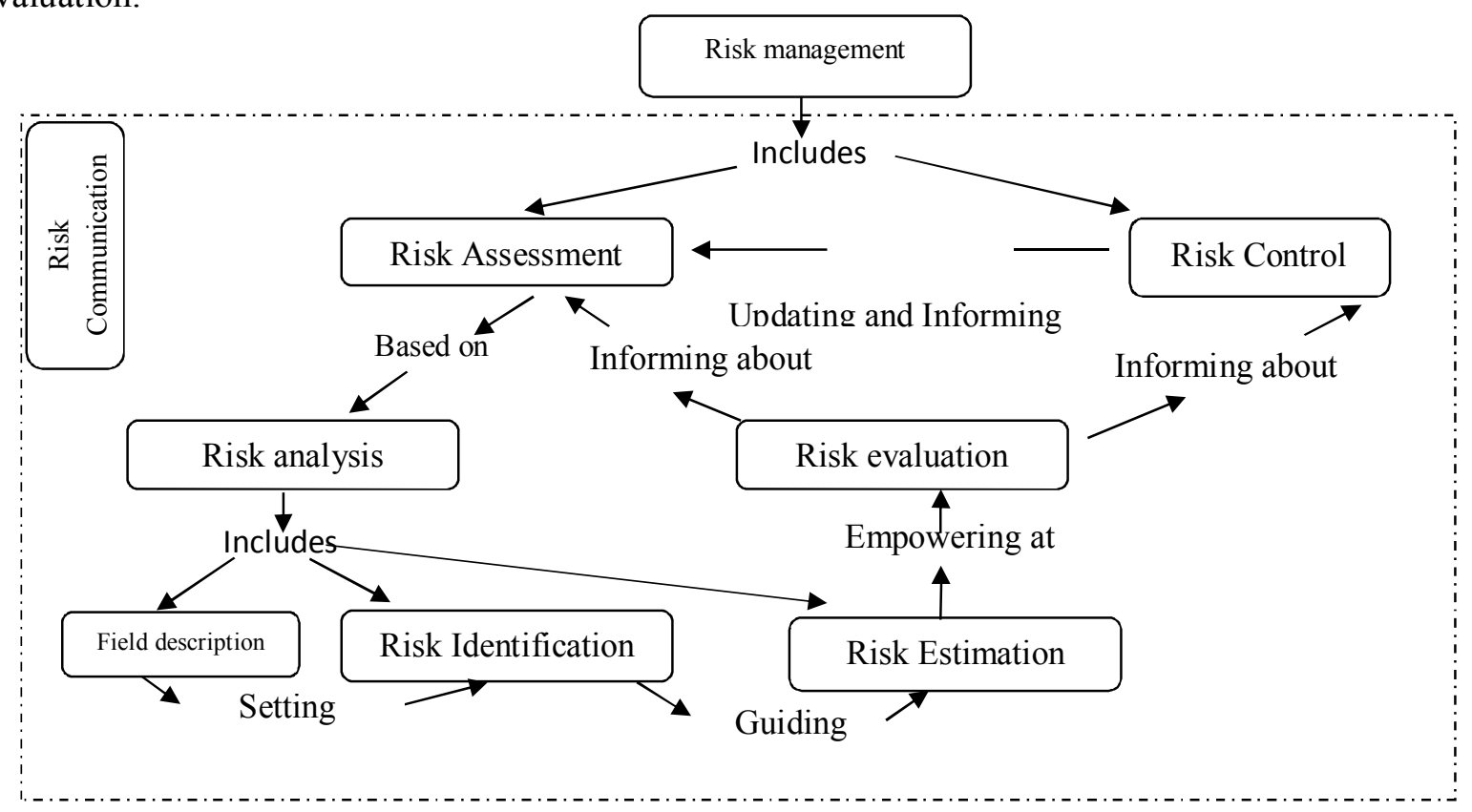

Fig. 2. Relationships between risk management process, risk analysis, assessment and control (Waller, 2003)

Risk analysis, in its turn, includes area description, risk identification and risk estimation. After identifying and estimating risks, it is possible to evaluate their effects in order to accept or reject them. Risk communication is an important aspect of risk management, which should be incorporated in all steps of the process.

This research proposes a method for risk assessment and management that is displayed in Fig. (3). In this method, after explaining goals, different scenarios of object deterioration should be quantified. Then, intensity and effects of deteriorating agents on risks origination and their quantitative and qualitative consequences should be considered. Thus, in risk evaluation step, it can be possible to recognize most important factors and scenarios. Assessment of risks helps conservators apply risk management in a systematic framework and make decisions about different methods of dealing with risk. Hence, proper conservation solutions to eliminate or minimize risks can be introduced.

$\begin{array}{llll}\text { Step } 1 & \text { Step } 2 & \text { Step } 3 & \text { Step } 4\end{array}$

\begin{tabular}{|c|c|c|c|}
\hline Goal determination: & $\begin{array}{l}\text { System: museum } \\
\text { climate condition }\end{array}$ & $\begin{array}{l}\text { Exploit consequences } \\
\text { from literature }\end{array}$ & $\begin{array}{l}\text { Objects deteriorations } \\
\text { in storage rooms }\end{array}$ \\
\hline Step 8 & Step 7 & Step 6 & Step 5 \\
\hline $\begin{array}{l}\text { Making decision about } \\
\text { storage conditions }\end{array}$ & $\begin{array}{c}\text { Sensitivity analysis and } \\
\text { assessing effects of each } \\
\text { factor }\end{array}$ & $\begin{array}{l}\text { Predicting future } \\
\text { conditions of objects }\end{array}$ & $\begin{array}{c}\text { Estimating Objects } \\
\text { service life }\end{array}$ \\
\hline
\end{tabular}

Fig. 3. Risk management steps with the goal of conservation of objects in storage rooms (Bahr, 1997, p.269)

Ideally, preventive conservation specialists should be able to quantify all risks that are exposed on a collection to determine the most effective methods to reduce hazards. In the meantime, required data to estimate risks magnitude is often unavailable; so it is necessary to use alternate methods to identify and quantify risks of museum collections. 


\section{Proposed quantitative approach for assessing environmental risk of museum objects}

Temperature and relative humidity are two environmental parameters that have gained the main emphasis in conservation studies of museum objects. For instance, Gray (1977), Feller (1994), Sebera (1994), Reilly et al. (1995), Michalski (2003), and Martens (2012) have studied effects of these parameters on chemical, physical, or biological degradation of objects. Each of these researches indicates the detrimental effects of improper amounts of these parameters on historical collections and objects. Despite the existence of advanced technology, conservation field still lacks methods and techniques to measure and quantify the interactions between temperature and relative humidity and their effects on reduction of objects' service life. Generally, in the case of not being able to use advanced storage and environmental monitoring techniques in museums, staffs usually do not gather long-term data of climate and microclimate parameters; it would almost be impossible to have an exact and appropriate interpretation of gathered data, because it's beyond the ability of ordinary employees. Therefore, it is essential to develop methods and approaches to empower museum curators and staffs with the basic skills to provide long-term assessments of environmental conditions, without requiring special knowledge of engineering science. Althou most conservation studies absolutely support the importance of environmental control in museums and their storage rooms, it is still a way beyond ordinary experiments in conservation management, which can help scientific principles to set internal climate conditions of museums.

\subsection{Determining a quantitative index for risk assessment}

Quantitative risk assessment needs a measurable index. Evaluating this index and its variations can demonstrate the effects of environmental conditions on museum objects. In this paper, objects' service life is considered as risk assessment index, due to its direct connection with vulnerability of objects. Service life is the amount of time that molecular structure of an object remains unchanged, despite being exposed to deteriorating factors (Feller, 1994, p.9). Measuring service life of objects provides a quantitative method to monitor and set storage conditions of collections. This method focuses on two indexes:

1- Preservation index (PI); which displays the effects of a constant amount of temperature and relative humidity on chemical deterioration of collections on a yearly basis. It gives general information about the amount of time needed for an organic material to degrade almost entirely. The main assumption for PI is the steadiness of temperature and relative humidity after their measurement. Of course, it should be mentioned that preservation index should not be used to determine service life of objects, but as a common criteria to examine current conditions on the expected service life of objects (Reilly et al. 1995). Eq. (1) can be used to compute preservation index for a given temperature $(T)$, relative humidity $(R H)$ and $\Delta H^{+}$as activation energy (The amount of energy, needed to activate 1 mole of a known material in chemical (Hydrolysis) reactions) of the object.

$P I=e^{\left(\frac{\Delta H^{+}-134.9 \times[R H \%]}{8.314 \times T}+0.0284 \times[R H \%]-28.023\right) / 365}$

2- Time-weighted preservation index (TWPI): By measuring this index, effects of different climates, which are combinations of temperature, relative humidity and their fluctuations on a specific period of time, on rate of deterioration can be calculated and provided as expected value for service life of an object. In other words, TWPI is weighted mean of PI values over a certain period of time (Reilly et al. 1995). Nishimura (1992) provided a formula to calculate TWPI as a recursive average of PI values as follows. In Eq. (2), $n$ is the number of time epochs, $T W P I_{n-1}$ is the average service life for the last $(n-1)$ epochs and $P I_{n}$ is the preservation index for the last epoch of time. 


\subsection{Case study-Cultural institutes of Bonyad museums}

Using a case study is one of the best methods to investigate and examine a scientific research. In this paper, recorded data of temperature and relative humidity of textile storage room of Bonyad museum is used for quantitative assessment of effects of climate conditions on service life of historical objects. Results of risk assessment can lead to prioritizing preventive conservation solutions in order to enhance service life of historical textiles, which in turn, affects management process for organizational resources of the museum.

Data for temperature and relative humidity has been recorded four times a day from September 2010 to February 2012; this $18^{\text {th }}$ month period is considered for calculation of objects service life. Fig. 3 shows the distribution of climate parameters in this period:
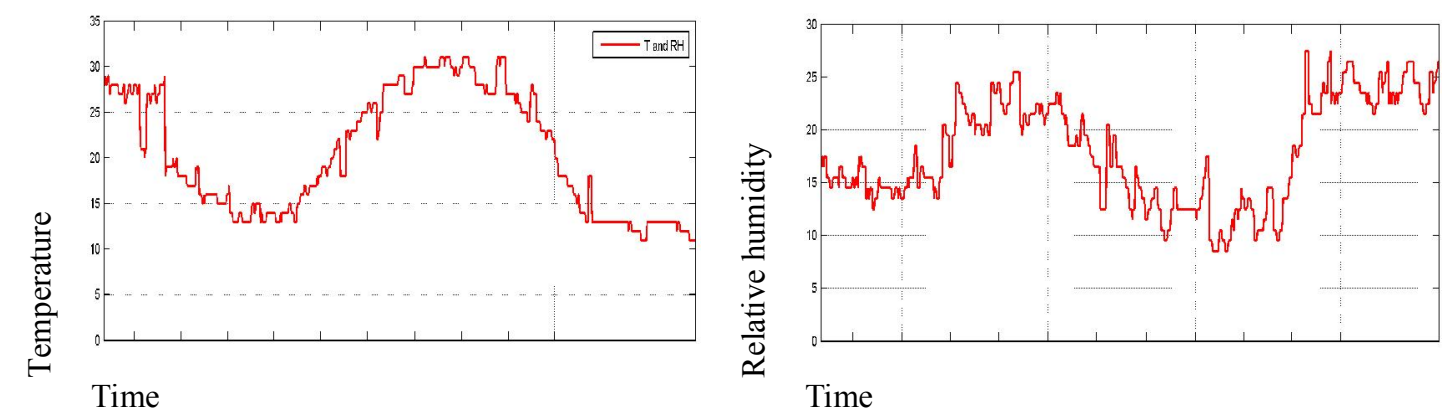

Fig. 1. Distribution of temperature (left chart) and relative humidity (right chart)

Table 1 provides a more detailed analysis of the environmental conditions of the textile storage room of Bonyad museum. Gratten and Michalski (2012) described standard environment of storage rooms with a temperature of 15 to 25 centigrade degrees and 50 percent relative humidity, while recorded data of textile storage room shows a range of 11 to 31 degrees for temperature and 8.5 to 27.5 percent for relative humidity that demonstrate the uncontrolled condition of the storage room.

\section{Table 1}

Data analysis for temperature and relative humidity

\begin{tabular}{llllllll}
\hline & & & & \multicolumn{2}{c}{$\begin{array}{c}\text { Season } \\
\text { Autumn }\end{array}$} \\
\hline Condition & & Spring 2011 & Summer 2011 & 2010 & 2011 & 2011 & 2012 \\
\hline Temperature & MAX & 31 & 31 & 20 & 18 & 22 & 13 \\
$\left(\mathrm{C}^{\text {o }}\right.$ & MIN & 22 & 18 & 13 & 11 & 13 & 11 \\
Relative & MAX & 21.5 & 21.5 & 24.5 & 27.5 & 25.5 & 26.5 \\
humidity (\%) & MIN & 9.5 & 8.5 & 13.5 & 21.5 & 18.5 & 21.5 \\
Temperature Fluctuation & 9 & 13 & 7 & 7 & 9 & 2 \\
\multicolumn{2}{l}{ Relative humidity fluctuation } & 12 & 1 & 11 & 6 & 7 & 5 \\
\hline
\end{tabular}

Table 2 shows a summary of temperature and relative humidity data for the studied storage room as well as PI and TWPI indexes. According to the table, estimated value for service life of the textile collection is predicted to be about 107.52 years. 
Table 2

Temperature, relative humidity, PI and TWPI for textile storage room

\begin{tabular}{|c|c|c|c|c|c|c|c|}
\hline Year & Month & Day & Monitor shift & $\mathrm{T}\left(\mathrm{C}^{\circ}\right)$ & RH (\%) & PI & TWPI \\
\hline \multirow[t]{4}{*}{2010} & \multirow{4}{*}{ Sep. } & \multirow{4}{*}{1} & First & 28 & 16.5 & 56.25 & 56.25 \\
\hline & & & Second & 28 & 16.5 & 56.25 & 56.25 \\
\hline & & & Third & 28 & 17.5 & 54.83 & 55.53 \\
\hline & & & Fourth & 29 & 17.5 & 48.44 & 52.95 \\
\hline \multirow[t]{4}{*}{2010} & \multirow{4}{*}{ Sep. } & \multirow{4}{*}{2} & First & 28 & 16.5 & 56.25 & 53.74 \\
\hline & & & Second & 28 & 17.5 & 54.83 & 53.95 \\
\hline & & & Third & 29 & 17.5 & 48.44 & 52.95 \\
\hline & & & Fourth & 29 & 17.5 & 48.44 & 52.25 \\
\hline \multirow[t]{4}{*}{2012} & \multirow{4}{*}{ Jan. } & \multirow{4}{*}{31} & First & 11 & 23.5 & 433.77 & 106.80 \\
\hline & & & Second & 11 & 24.5 & 421.49 & 106.90 \\
\hline & & & Third & 11 & 24.5 & 421.49 & 107.01 \\
\hline & & & Fourth & 11 & 24.5 & 421.49 & 107.11 \\
\hline \multirow[t]{4}{*}{2012} & \multirow{4}{*}{ Feb. } & \multirow{4}{*}{1} & First & 11 & 25.5 & 409.55 & 107.22 \\
\hline & & & Second & 11 & 25.5 & 409.55 & 107.32 \\
\hline & & & Third & 11 & 26.5 & 397.95 & 107.42 \\
\hline & & & Fourth & 11 & 26.5 & 397.95 & 107.52 \\
\hline
\end{tabular}

Fig. 4 shows complete variations of predicted service life during the 18 months. As it is obvious, TWPI value increases in cold seasons and it decreases with temperature and relative humidity decrease.

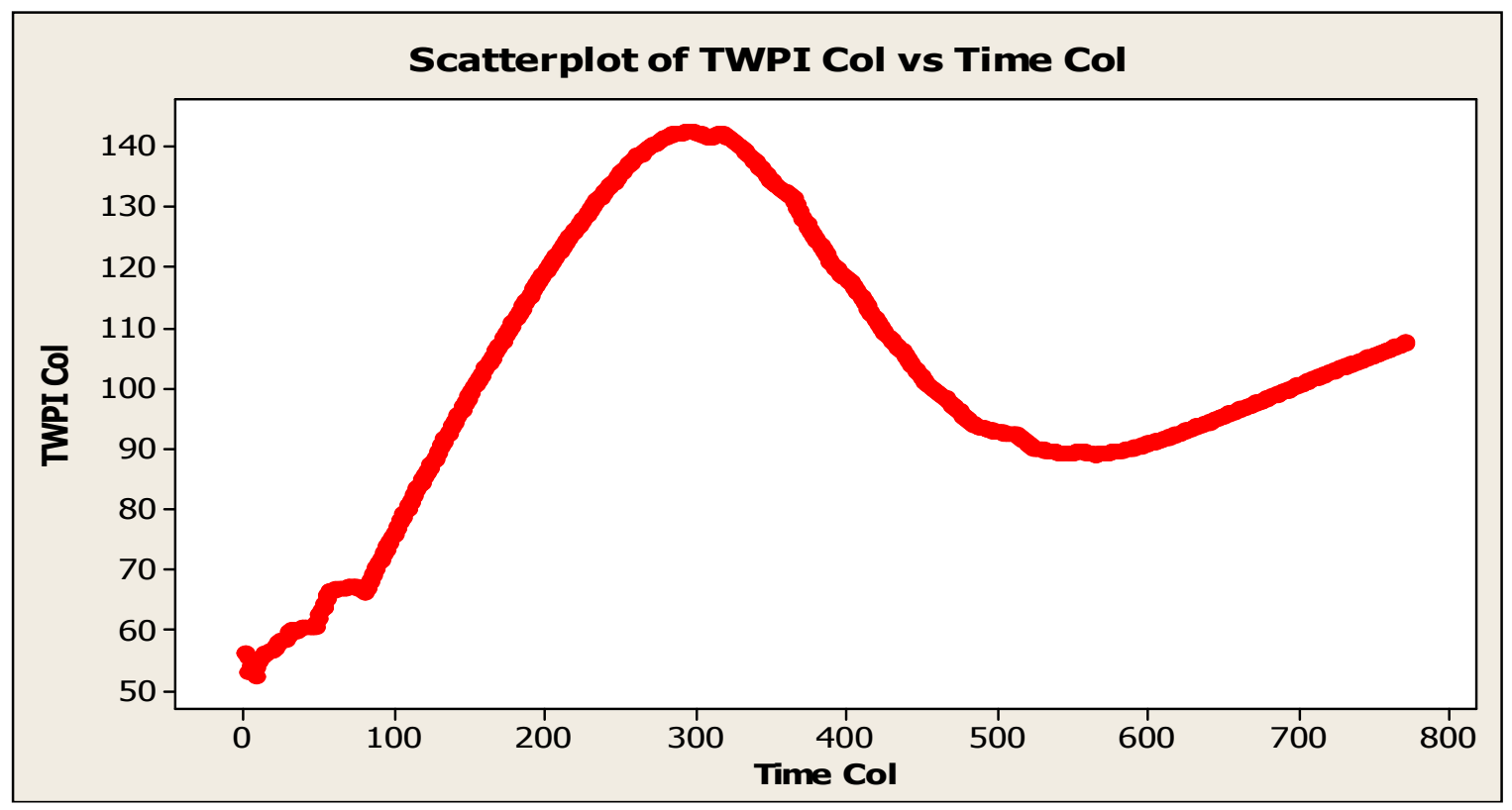

Fig. 4. Distribution of TWPI during 18 months

\subsubsection{Sensitivity analysis}

Sensitivity analysis is one of the best methods to examine the effects of parameters changes and data alternation in quantitative approaches. Therefore, sensitivity of the results to fluctuations of both temperature and relative humidity is analyzed and TWPI for these circumstances is calculated:

1- Analyzing sensitivity of service life to temperature changes: in order to examine the effects of temperature on service life of collection more precisely, the possibility of temperature reduction in hot seasons is considered and its effects on TWPI is calculated based on Eq. (1) 
and Eq. (2). Summary of the results are displayed on Table (3) that can be a considered as an encouragement to show efficiency of methods that aim to control storage temperature.

Table 2

Sensitivity analysis of TWPI against temperature

\begin{tabular}{|c|c|c|c|}
\hline 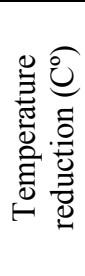 & 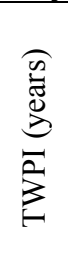 & 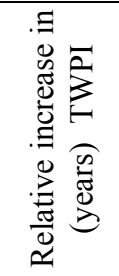 & 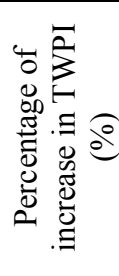 \\
\hline 1 & 118 & 10.47 & 10.28 \\
\hline 2 & 130 & 22.29 & 21.50 \\
\hline 3 & 142 & 34.58 & 32.71 \\
\hline 4 & 155 & 47.59 & 44.86 \\
\hline 5 & 169 & 61.27 & 57.94 \\
\hline 6 & 183 & 75.55 & 71.03 \\
\hline 7 & 198 & 90.35 & 85.05 \\
\hline 8 & 213 & 105.57 & 99.07 \\
\hline 9 & 229 & 121.079 & 114.02 \\
\hline 10 & 244 & 136.74 & 128.04 \\
\hline
\end{tabular}
Service life

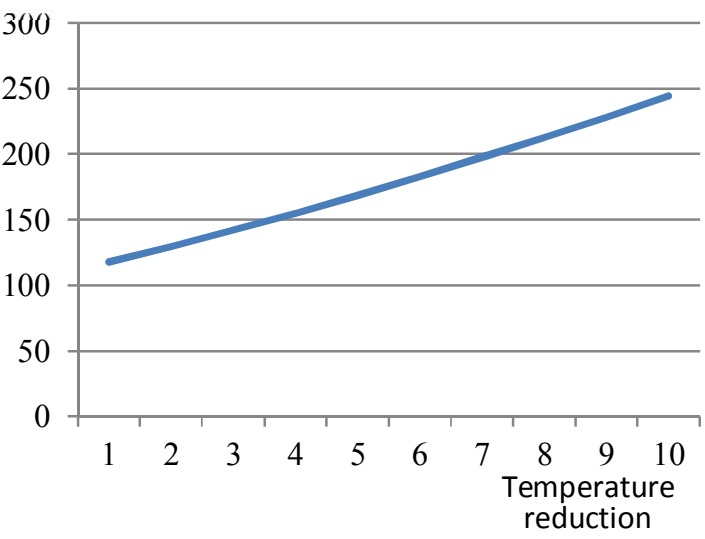

Fig. 5. TWPI increase against reduction of temperature in hot seasons

2- Analyzing sensitivity of service life to relative humidity changes: relative humidity of the storage room increases during winter and autumn, therefore, the possibility to control and decrease it in these seasons has been considered and Table 4 displays summary of the results, which emphasize on the effect of RH reduction on the service life of textile collection.

Table 3

Sensitivity analysis of TWPI against relative humidity

\begin{tabular}{|c|c|c|c|}
\hline 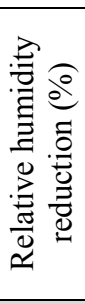 & $\vec{F}$ & 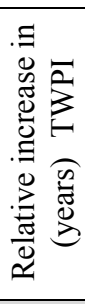 & 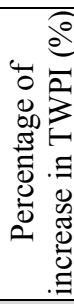 \\
\hline 1 & 108.13 & 0.61 & 1.06 \\
\hline 2 & 108.74 & 1.21 & 1.63 \\
\hline 3 & 109.33 & 1.80 & 2.18 \\
\hline 4 & 109.91 & 2.38 & 2.72 \\
\hline 5 & 110.48 & 2.95 & 3.25 \\
\hline 6 & 111.04 & 3.52 & 3.78 \\
\hline 7 & 111.60 & 4.07 & 4.30 \\
\hline 8 & 112.14 & 4.61 & 4.80 \\
\hline 9 & 112.67 & 5.14 & 5.30 \\
\hline 10 & 113.19 & 5.67 & 5.79 \\
\hline
\end{tabular}

Service life

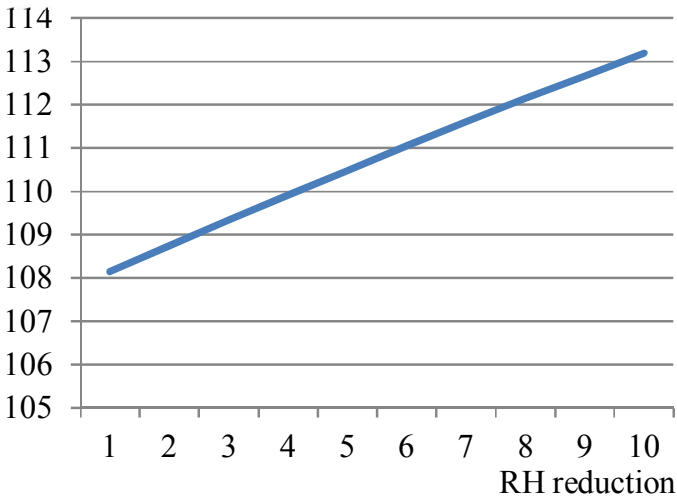

Fig. 6. TWPI increase against reduction of relative humidity in cold seasons

Comparing results of these tables illustrate that although reduction of temperature and relative humidity, (within the standard range of storage spaces for museum objects), lead to enhancement of service life for the studied collection, TWPI is more sensitive to temperature. Results show that reduction of each degree of temperature leads to an average 12.4 years increase in service life of objects while reduction of each percent of relative humidity cause an average of 0.74 years enhancement of tis service life. 


\subsubsection{Linear regression}

Finally, linear regression has been used to generate a short-term prediction of TWPI, with time, as explanatory variable. Eq. (4) displays the linear regression of TWPI as response variable with a cubic independent variable (time) and linear parameters $\left(\beta_{0} \ldots \beta_{3}\right)$. Coefficient of determination for this regression model $\left(\mathrm{R}^{2}\right)$ equals $84.3 \%$, which shows a good linear relation between TWPI and time.

$$
T W P I=24.3+0.879 T-0.00229 T^{2}+0.000002 T^{3}
$$

Since data of temperature and relative humidity is analyzed on seasonal basis, winters' method of "time series" is applied as a short-term forecasting seasonal model to estimate TWPI at the end of next season, with 95\% confidence level. This will help curators and conservators to estimate the effectiveness of their short-term activities on collections. Fig. 7 and Table 5 display forecasting results of this method:

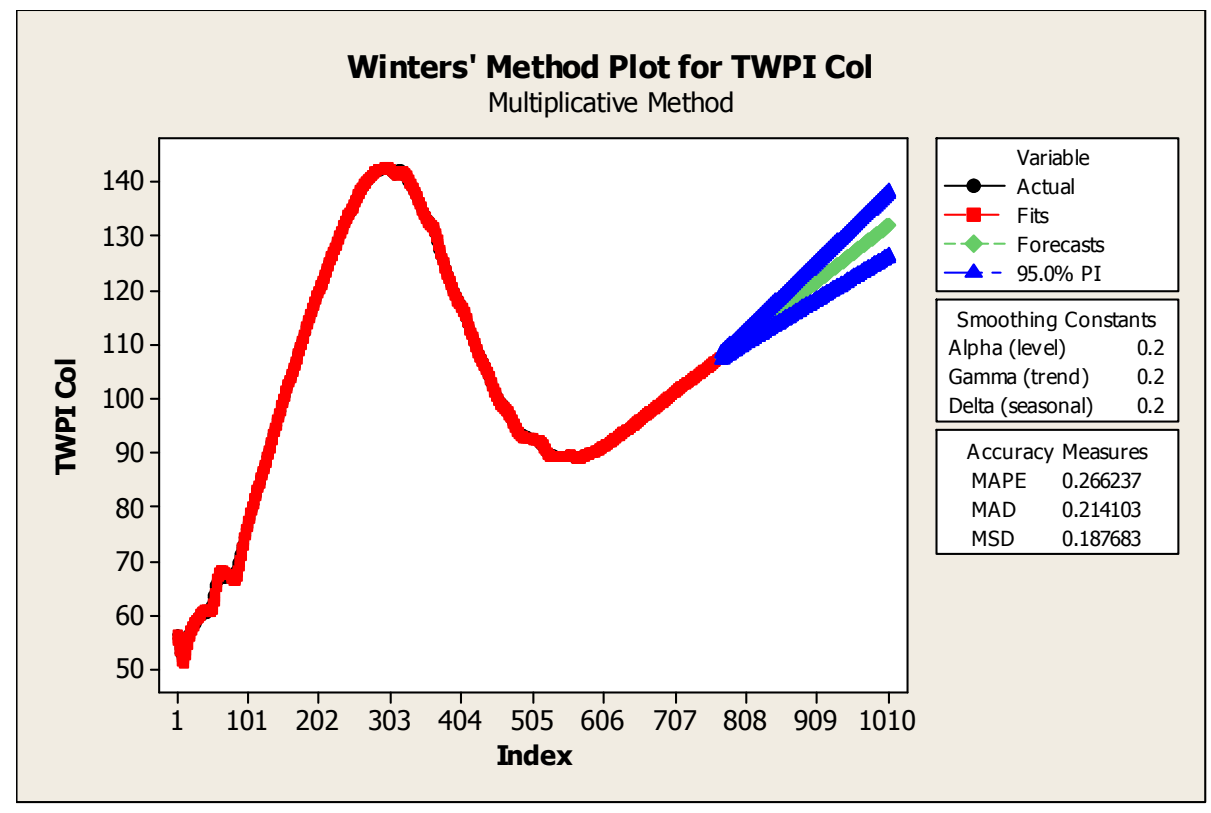

Fig. 7. Seasonal forecast for TWPI with $95 \%$ confidence level

Table 4

Short-term prediction of TWPI for next two months of textile collection

\begin{tabular}{lccc}
\hline Forecasting period & Predicted TWPI & lower limit of forecast & Upper limit of forecast \\
\hline 15 days & 113.685 & 112.021 & 115.349 \\
30 days & 119.844 & 116.771 & 122.917 \\
45 days & 126.003 & 121.499 & 130.507 \\
60 days & 132.162 & 126.220 & 138.103 \\
\hline
\end{tabular}

As it is displayed in Table 5 and Fig. 7, service life of collection will show an increase during next two months, which is because of the effects of low temperature in the short-term future. But the noteworthy matter is that the overall TWPI has a decreasing trend; comparing predicted TWPI (132.162 years) with TWPI value from the same time of last year (136.422 years) can support the idea that current storage conditions have an obvious detrimental effects on the textile collection due to lack of control on temperature and relative humidity.

\section{Conclusion}

Although most conservators and museum managers are aware of detrimental effects of improper amounts temperature and relative humidity, their gradual risk is often ignored. Therefore, this paper has tried to introduce a quantitative method to study and investigate risks that are exposed to museum 
objects, as a function of collection management in cultural heritage system. The main objective of museums is to preserve historical collections of cultural properties, which guaranties their development and display, so, it is essential to spend more organizational resources on conservational activities. In this paper, service life has been used as a quantitative index of risk assessment process to investigate simultaneous effects of temperature and relative humidity on works of art. According to results of this research, reduction of temperature during hot seasons and keeping it in the standard range of storage for museum collections is the most effective preventive solution to reduce risks of environmental conditions in the studied storage room. Besides using air conditioning systems, decisions about moving collections to a better storage area in other parts of buildings, with lower average of temperature, can help museum managers to decrease risks of collections with little investments and expenses.

\section{References}

AIC (2003). AIC Definitions of Conservation Terminology. In AIC Directory, American Institute for Conservation of Historic and Artistic Works, p. AIC-22. Also available at http://www.conservation-us.org

Ashley-Smith, J. (1999). Risk assessment for object conservation. Oxford: Butterworth Heinemann, XIV.

Bacci, M., Picollo, M., Porcinai, S., \& Radicati, B. (2000) Evaluation of the museum environmental risk by means of tempera-painted dosimeters. Thermochimica Acta, 365, 25-34.

Baer, N.S. (1991). Assessment and Management of Risks to cultural Property, in Science, Technology and European Cultural Heritage. Butterworth-Heinermann, Oxford, 27-36.

Bahr, N.J. (1997). System Safety Engineering and Risk Assessment: A Practical Approach. Taylor and Francis, Washington, D.C.

CCI. (1985). Canadian Conservation Institute. CCI Notes. Ottawa: Canadian Conservation Institute.

ECCO. (2013). European Recommendation for the Conservation and Restoration of Cultural Heritage.

Feller, R.L. (1994). Accelerated aging: photochemical and thermal aspects. Ann Arbor, MI: Edwards Brothers.

Grattan, D., \& Michalski, S. (2012). Environmental Guidelines for Museums. CCI, Ottawa: Canadian Conservation Institute.

Gray, G. G. (1977). Determination and significance of activation energy in permanence tests. In Preservation of Paper and Textiles of Historic and Artistic Value, J. C. Williams, ed. American Chemical Society, Washington, D.C., Advances in Chemistry Series 164:286-313.

Huijbregts, Z., Kramer, R.P., Martens, M.H.J., Van Schijndel, A.W.M., \& Schellen, H.L. (2012). A proposed method to assess the damage risk of future climate change to museum objects in historic buildings. Building and Environment, 55, 43-56.

ISO 31000 (2009). Risk Management- Principles and guidelines.

Keene, S. (1996). Managing conservation in museums. London: Butterworth Heinemann, XI.

Martens, M.H.J. (2012). Climate risk assessment in museums: degradation risks determined from temperature and relative humidity data. Thesis for Degree of doctor of Building Physics and Services, University of Eindhoven.

Michalski, S. (1994). A systematic approach to preservation: Description and integration with other museum activities. Preprints of the Congress on Preventive Conservation: Practice, Theory and Research, Ottawa. London: International Institute for Conservation of Historic and Artistic Works. 8-11.

Michalski, S. (2003). Double the life for each five-degree drop, more than double the life for each halving of relative humidity. ICOM committee for conservation, 13 th triennial meeting Rio de Janeiro preprints, 1, 66-72.

Michalski, S. (2004). Care and preservation of collections, In: Running a Museum: A Practical Handbook/ edited by Boylan. P. Paris: International Council of Museums \& UNESCO, 51-90. 
Nishimura, D.W. (1992). Color Microfilm Dark Stability Research. Final Report to the Commision on Preservation and Access.

Pinheiro, A.C., \& Macedo, M.F. (2009). Risk assessment: A comparative study of archive storage rooms. Journal of Cultural Heritage, 10, 428-434.

Reilly, J.M., Nishimura, D.W., \& Zinn, E. (1995). New tools for preservation, assessing long-term environmental effects on library and archives collections. Image Permanence Institute, Rochester Institute of Technology, ISBN 1-887334-46-7.

Reilly, J.M., Stub Johnsen, J., \& Aasbjerg Jensen, L. (2007). Documenting and optimizing storage conditions at the National Museum of Denmark, Museum Microc limates', Contributions to the Copenhagen conference. Published by The National Museum of Denmark.

Schieweck, A., Markewitz, D., \& Salthammer, T. (2007). Screening emission analysis of construction materials and evaluation of airborne pollutants in newly constructed display cases, Museum Microc limates. Contributions to the Copenhagen conference, Published by The National Museum of Denmark.

Schijndel, A.W.M. van, Schellen, H.L. \& Martens, M.H.J. (2011). Modeling multiple indoor climates in historic buildings due to the effect of climate change. Proceedings of the NSB2011, Tampere. 817-825.

Sebera, D.K. (1994). Isoperm: An Environmental Management Tool. The Commission on Preservation and Access, Washington, D.C.

Stovel, H. (1998). Risk Preparedness: A Management Manual for World Cultural Heritage, ICCROME.

Waller, R.R. (1994). Conservation risk assessment: a strategy for managing resources for preventive conservation, In: Preventive conservation practice, theory and research: preprints of the contributions to the Ottawa congress, Roy, Ashok (ed.); Smith, Perry (ed.); IIC. London: International Institute for Conservation of Historic and Artistic Works, p. 12-16.

Waller, R.R. (1995). Risk management applied to preventive conservation, in Genoways, H H, Hawks, C A and Rose, C L (eds), Storage of natural history collections: A preventive conservation approach. Iowa City, Society for the Preservation of Natural History Collections, 21-28.

Waller, R.R. (1999). Incorrect Temperature as a Risk- How Significant Is Its. Natural Science Conservation Group Newsletter, 10(5), 16-21.

Waller, R.R. (2003). Cultural property risk analysis model: development and application to preventive conservation at the Canadian Museum of Nature. Göteborg: Acta Universitatis Gothoburgensis, XVI, 189 p. : fig., tables ; 28 cm. (Göteborg Studies in Conservation, 13), Doctoral Dissertation, Göteborg University. Institute of Conservation, Göteborg, Sweden.

Waller, R.R., \& Michalski, S. (2005) 'Effective preservation: from reaction to prediction, Conservation. The Getty Conservation Institute Newsletter, 19(1), 4-9.

Waller, R.R., \& Shelton, S. (1989). Risk Management Strategies Applied to the Development of Pragmatic Solutions to Collections Storage Problems. In Programme and Abstracts of the Fourth Annual Meeting of the Society for the Preservation of Natural History Collections, Calgary, 32. 